\title{
OBITUARY
}

\section{ANDREW OLIVER FERGUSSON ROSS, M.D., D.P.H.}

Dr. A. O. Fergusson Ross died on June 3, 1954, after a long illness. He served in sea-going ships in the first world war as a surgeon probationer in the Royal Navy and returned to Edinburgh to graduate M.B., Ch.B., in 1917. He later served as specialist in genito-urinary surgery and venereal diseases with Parnell at the Royal Naval Hospital at Haslar. This experience undoubtedly inspired his great interest in the problems of venereal disease in seafarers which was to become such an outstanding part of his life's work. In 1921 he graduated M.D. (Edin.), having presented a thesis on "Gonococcal Arthritis", and in 1926 he obtained the D.P.H. at Liverpool where he had been appointed medical officer in charge of the Seamen's Dispensary in 1924. Appointment as Honorary Surgeon to the Lock Department at the Royal Infirmary and as Lecturer on Specific Diseases at the University in Liverpool followed in 1931. These appointments marked his full acceptance in Liverpool as a consultant in a specialty of outstanding importance in such a large city and seaport, and his professional knowledge and skill were quickly recognized by his colleagues. In 1934 he opened the Central Clinic at Mill Road Infirmary, Liverpool, in association with excellent in-patient facilities, and he became consultant to Clatterbridge Hospital, Cheshire, in 1947. With the inception of the National Health Service in 1948, Dr. Ross was appointed Regional Adviser to the Liverpool Regional Hospital Board and Senior Consultant in Venereal Diseases at Liverpool Royal Infirmary.

His professional work was founded on an exceptionally broad background of knowledge and was distinguished by his alertness and critical progressiveness. His teaching, both academic and clinical, was erudite but always crystal clear. Both practice and teaching were impressively coloured by his modesty, unfailing courtesy, and kindly understanding. To visit his clinics or to discuss medical problems with him was a stimulating experience, for he was usually in the van of all progressive develop- ments although his sound clinical judgment and critical mind rejected "stunts" and protected his patients from unsound schemes of treatment. His early naval service and his constant association with seafarers inspired his special interest in their venereal disease problems, and, to meet their special circumstances, he developed in 1924 an intensive scheme of treatment of early syphilis, which was later adopted by many other centres dealing with sailors. He was decorated by the Norwegian Government in recognition of his services to Norwegian sailors during the second world war. In September, 1953, he gave the inaugural lecture of the first course at the Rotterdam Port Demonstration Centre, and was introduced by the Director, Dr. E. H. Hermans, Sr., as " the acknowledged pioneer in the field of maritime venereal disease control ". With his colleagues in Liverpool he conducted the early field trials of penicillin in syphilis, and their report, intentionally delayed to permit of follow-up studies in the patients treated, might well have been the first announcement of this dramatic development in the treatment of syphilis.

Dr. Ross was a delightful colleague and host. We remember particularly his integrity, sincerity, and that effervescent sense of humour which blended to form such a full and charming personality. Many will recall with pleasure the annual meeting of the B.M.A. in Liverpool in 1950 at which he organized a successful joint meeting of the sections of dermatology and venereology. His sage comment will be missed in the Council and at the meetings of the Medical Society for the Study of Venereal Diseases, in the Editorial Committee of this Journal, and in the Venereologists Group Committee of the B.M.A.

Dr. Ross faced his long illness with great courage and calm resignation which were sustained by his strong religious faith. He is survived by Mrs. Ross, three sons and a daughter, to whom we extend our sympathy.

R. L.

S. M. L. 